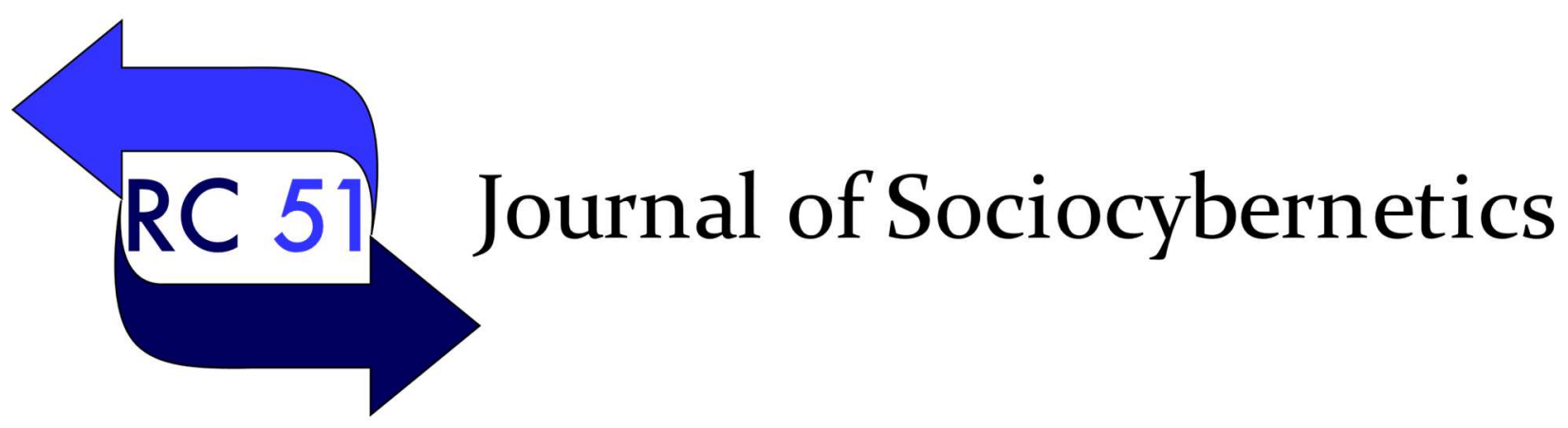

Journal of Sociocybernetics ISSN 1607-86667

\title{
Narrative Self-Reference and the Assessment of Knowledge
}

\author{
Maximilian Roßmann \\ Karlsruhe Institute of Technology
}

\begin{abstract}
The concept of narrative self-reference incorporates selected aspects of literary theory into the theory of selfreferential systems in order to sharpen its analytical and explanatory perspective on certain linguistic structures. Since cybernetics and systems theory focus mainly on computer-aided metaphors and information, the narrative approach provides a better insight into meaning. Narrative self-reference is the narrated sequence of events that constructs a simplified self-image in the referred system-environment relations (e.g. in history or future visions), and thereby stabilizes the system. In practice, these narratives become the pivot of the social and psychic system and sketch contingent collectivities and actions. Since narrative self-reference is not static but rewritten, continued and entangled in various present practices, it offers flexibility against new and disappointed expectations as well as stability for accountability and planning. In this context further theoretical concepts of legitimation theory, sociology of technology, and the philosophy of science and neuroscience are compared. In summary, this article formulates a systems-theoretical research interest in the negotiating power of narratives that create system boundaries for cooperation and a common basis for the evaluation of knowledge.
\end{abstract}

url:

\section{Introduction.}

The recent strengthening of populism was like the awakening of a monster of postmodernist dreams. Now it becomes clear what it means when scientific facts are contrasted with alternative facts or scientific explanations are labeled as an interest-guided projection of mere paradigms of a false elite with a false consciousness: Necessary political measures for climate change and peace lose their foundation and are blocked and reversed. Without a universal criterion as the guardian of the right truth, it seems that society lacks the common ground for its preservation and a future worth living. Where have objectivity and rationality disappeared?

The post-truth crisis is not a general loss of scientific authority or scientific accuracy, but a crisis and neglect of common grounds to evaluate knowledge-based policy programms since embedded facts have practical meaning (see Jasanoff \& Simmet, 2017). To address this problem, I propose the perspective on narrative self-reference as the pivot of collective and individual meaning and action. In summary, this article argues for reflection of the function of narratives for orientation by providing system boundaries that support and cross stand to the unity of a scientific system (part 4). Because societies are based neither entirely on evidence nor on consent, a narrative negotiation makes alliances of power and truth meaningful (part 4.1). This concept shall give a system- 
theoretical basis for further studies on narratives in policy and technology genesis research, assessment and modeling practice.

To provide this perspective, I interpret the function of narratives in terms of self-referential systems (part 3). In Niklas Luhmann's systems theory, the term narrative is not used, but other terms have a similar function, like e.g. "parallel poetry", "historicity", "episode formation", "reflection", "dramatization". I argue that the term narrative helps to explain and to give insight into the selfreferentiality of individuals and collective actors. The concept of narrative self-references provides a distinction of only externally ascribed collectivity and self-referential systems with the capacities of autonomy, collective action, and accountability. In the following parts, four theoretical approaches are interpreted in this context. Each highlights another important aspects and procedures of complexity reduction in the formation of shared narratives that impact personal and cooperate identity, legitimation and the option of collective action:

3.1. The "entanglement in a role play" is based on institutional procedures like legal proceedings and political elections and mass media to produce legitimation (Luhmann, 2013, p. 87).

3.2. The internet provides new and contested technical infrastructures for emerging self-reference by means of controlled feedback Dolata \& Schrape, 2018.

3.3. The make-believe theory takes narratives as props and distinguishes authorized imaginary modelworld comparisons on basis of "public rules" (Frigg, 2010; Walton, 1990).

3.4. The "narrative self-constitution view" completes the "autobiographical narrative" with the pragmatically approving on "reality constraints" (Schechtman, 2015, p. 398).

All approaches are compared by reference to the above-mentioned function of self-referentiality and narratives. To point out the meaning of narratives, I shortly review some aspects of the narrative theory (part 2).

\section{Narratives as the sequential organization of events}

"531. We speak of understanding a sentence in the sense in which it can be replaced by another which says the same; but also in the sense in which it cannot be replaced by any other [...], something that is expressed only by these words in these positions. (Understanding a poem.)"

(Wittgenstein, 1984)

Narratives are traditionally the subject of literary studies, but recent cognitive science, sociology, cultural studies, political science and the philosophy are increasingly paying attention to them. Brown, 2017 gives an excellent overview of narrative approaches in these fields and their impact on environmental psychology research. Narrative analysis is about "meaning encoded in language" and “recipients' understanding” (Hermwille, 2016, p. 238). We make sense by following a linguistic sequential organization instead of looking side by side at propositions and arguments (see Wittgenstein, 1984, § 531). Aristotle describes the mimesis of a tragedy as "an imitation of an action that is serious and has a wholeness in its extent" (Aristoteles, 2006, 1449b.24), that is, "has a beginning, a middle, and an end," meaning that nothing is necessary before or afterwards in order to make it a whole (Aristoteles, 2006, 1450b.26). The sequentiality of events "create the order of time." (Abbott, 2011, p. 4). In order to clarify the term of the narrative, I mainly refer to the derivation, definition, and distinction in "Cambridge introduction to narrative":

"narrative is the representation of events, consisting of a story and narrative discourse; a story is an event or sequence of events (the action); narrative discourse is those events as represented. [...] we never see a story directly, but instead always pick it up through the narrative discourse."

(Abbott, 2011, pp. 19-20) 
The following parts focus on the analysis of the rhetorical power by carrying us from A to B, guiding our perception on a selection of relevant aspects, as only a "lack of narrative continuity or coherence" causes hesitation (Abbott, 2011, p. 14).

\subsection{Focalized mediation and language oriented analysis of a discursive-internal world}

Stories are embellished and narrated in various ways. In practice, a "story is always mediated (constructed) by narrative discourse." (Abbott, 2011, p. 21). A story can only make a difference in practice, thus "you could say that history does not really happen in the past but must wait until someone narrativizes the past" (Abbott, 2011, p. 155). Two narrative discourses can frame the same story but evoke other feelings or conclusions. We could, for example, imagine how the planning process of a power plant is narrated from the planners' and an opponents' view or how the court case of Eichmann in the medial report of state Israel differs from Hannah Arendt's report (see part 4.1). For heuristic-analytical reason and in reference to literary theories, we compare narratives in forms of contingent whole referable sequential language structures that focalize a story - if we were stuck on different points of view or the authors' background, there was no benefit of the term narrative in contrast to, e.g. structure, discourse, schema or concept. In contrast to discourse analysis, "narrative analysts ask rather what language and speech does, than what it means or presupposes" (Hermwille, 2016, p. 238). In many cases, the narrator focalizes "the lens through which we see characters and events" (Abbott, 2011, p. 73). On one hand, we can analyze narratives with means of masterplots, typical genres, structures, and stereotypes (Abbott, 2011, p. 58; Jones \& McBeth, 2010). On the other hand, we can analyze narratives in juxtaposition to their practice or history, and in traditions like Marxism, psychoanalysis, colonialism or feminism (Culler, 2011, pp. 135-146):

"For anything that seemed to make sense, literature could make it nonsense, go beyond it, transform it in a way that raised the question of its legitimacy and adequacy."

$$
\text { (Culler, 2011, p. 41) }
$$

Both, fiction and non-fiction cause powerful effects on their audience. The narrative discourse frames an internal world in its own rules and inherent-discursive meaning that is "indifferent to [...] extralinguistic reality" (Bruner, 1990, p. 44). Thus, "literary fictions often contain statements that, when judged from a real-world perspective, are evaluated as false and that is about objects that do not exist concrete spatiotemporal entities" (Salis, 2016, p. 245). Being asked to imagine or to believe a story can make a difference for the demands of the internal world of a narrative. But it is neither necessary nor possible to distinguish whether a narrative is a fiction or non-fiction by the narrative reference to the story (John Searle discussed in Abbott, 2011, p. 148). Whether it is actually a nonfictive story is only apparent in the ascribed "referential function" to something real in the world of the recipient (Abbott, 2011, p. 153). Beyond a "true story" claim of extralinguistic reference, narratives are discussed in terms like "believability" and "coherence" since they are "less about facts and more about meanings" (Brown, 2017, p. 219).

\subsection{Closure, suspense, and surprise as the driving force for continuity and coherence}

A story must neither be told to its end nor the world described in every detail. When we follow a narrative from its beginning, we start to expect and look for closure that is the resolution of a problem or conflict, as "satisfaction to desire, relief to suspense, and clarity to confusion" confirming a masterplot at the end of the narrative (Abbott, 2011, pp. 56-64). Mary Morgan describes the ordering of selected material, categories, and internal divisions that make the narrative into a coherent whole as a "detective or forensic casework, be it fictional or factual" (2017, p. 93). On every step in the narrative, we assume coherence in a "way of normalizing those events" (Abbott, 2011, 
p. 44) - the "underlying" rules are not expressed by propositions but shown. We expect at minimum completeness and consistency (Crasnow 2017, p. 12), but as a representation of a whole external real world, a narrative would always be necessarily incomplete and thus meets contingent focalization. Driven by suspense and surprise, narratives can even transcend the boundaries of space and time as we confront the protagonists' dreams and thoughts to gain further impressions of their motivation, expectation, or belief.

Suspense drives us further into the story and keeps us on reading and imagining. With suspense, we continuously follow a sequence of events and experience the pleasure to be carried "from one point to another", while an "explanatory gap" does not necessarily matter and leaves "room for further narrative discourse to fill this gap" (Abbott, 2011, pp. 195, 211). Woken expectations let us notice and highlight turning-points and contingencies in a way that makes a story worth telling and listening (Crasnow, 2017, p. 12). If we would insist on "someone to a character type", we denied "her capacity to surprise us with behavior that exceeds the limits of the type" (Abbott, 2011, p. 136). Thus, the surprise may confront us with our own expectation of normality, types, genres, and masterplots. The narrative gains its spurned rhetorical power in immersion when we fail to notice that "the attraction of narrative coherence has overridden both reason and the evidence of the senses" (Abbott, 2011, p. 45). We continuously expect closure, but when a narrative ends before closure is reached, it causes the even more interesting effect: By not closing, many powerful narratives "don't tell us what to think but cause us to think" (Abbott, 2011, p. 63). Our imprisonment in "the masterplots we grow up with" (Abbott, 2011, p. 189) can be critically addressed in such reflection - are we the ones who imagine, follow, notice or cling to stereotypes and rigid ideology? This practical orientation on narratives, implied normality expectations and emerging perspectives, will be discussed in the following part.

\section{Narrative self-reference}

To provide theoretical connectivity, the first part focuses on self-reference in Luhmann's social systems theory and gives reasons for a partial interpretation of some theoretical terms as narratives. The later four subparts give theoretical examples of further institutional, technical, authorial, and pragmatic dependencies for the constitution of psychic and social systems with means of narrative self-reference.

Self-reference is the reference of the system to itself and thus the constitutional condition of selfreferential systems (Luhmann, 1987, p. 31). Self-referential systems are non-trivial machines, since their actual output does not depend only on an objectively understood input, but accounts for it in a function found from previous operations (von Förster, 1972, p. 36). Non-trivial machines are characterized by structure but are practically unpredictable in their operation. Luhmann distinguishes between three forms of self-reference based on the grounding self-referential distinction:

1. "We want to speak of basal self-reference when the distinction between element and relation is at the bottom" (Luhmann, 1987, p. 6oo)

2. "We want to speak of reflexivity (processual self-reference) if the distinction between before and after elementary events is at the basis." (Luhmann, 1987, p. 601) 
3. "We want to speak of reflection when it is based on the distinction between system and environment [...] in which case the self is the system to which the self-referential operation belongs" (Luhmann 1987, p. 601); "and in order to mark the difference to a mere creation of the unity of the system (as seen by an external observer), in the case of reflection we speak not of unity but of identity." (Luhmann, 1992, p. 482)

Basic self-reference generates models of element relations that recreate in the case of communication and thought. The processual self-reference refers to sequentiality of events in order to make sense. This already fits our definition of a narrative as lingual reference to a sequence of events. The reflexive observation tells a story; and as reflection, it tells a story that implies its distinction from its environment in this self-image. The basal operation in form of communication or thought then becomes an addressable self. The narrative concept is not namely intended in the theory of social systems for self-reference. However, Luhmann refers to historicity as the "basis of meaning" that has been built up in "a history of experiences and communication processes" (1971, p. 43). For systems, the experience is "structurally relevant information" and leads to the "restructuring of meaningful premises of the processing of experience" (Luhmann, 1971, p. 41). In the current experience processing, narrative self-reference becomes the form and relevant conglomeration of self-ascribed experiences that provide expectation. For this purpose, experiences must be assigned to the identity, "in the case of psychic systems [...] the immediately experienced consciousness, with which it knows to be one", and in the case of social systems "a context of coherent actions that stand out from an environment" (Luhmann, 1971, pp. 81-83). In the same way, as on the horizon of the past, self-reference can also be told on the horizon of a fictional future (Luhmann, 1971, pp. 59-60). Action is distinguished from behavior when the change of state of a system is assigned to it - by others and in self-reference (Luhmann, 1992, p. 141). In the case of reflection, the individual action is attributed to the system, and the identity becomes a latent phase in the form of a representation of the unity of the system in the system - as opposed to the pure constitutive principle of presence (Luhmann, 1987, p. 618).

In our observation of the narrative self-reference of systems we aim to follow the under-complex, but the contingent observable orientation of the system in written or spoken language. We make sense of our observations with means of our psychic ability of "episode formation" (Luhmann, 1987, p. 369). In the normal understanding, a system is described as driven by interests and dependencies towards the environments. In the narrative understanding, we make clear the reflected dependencies on the horizon of narrative closures. In scientific foresight, this shift was recently reflected as the “Narrative Turn" from "storytelling" to "story-listening” (Schwarz, 2015, p. 512). Bruner noticed a similar turn in cognitive-science from computational metaphors to narrative interpretation (Bruner, 1990, pp. 1-30). To sum up, Narrative self-references are simplified narrative self-images that reflect their system-environment relationship, provide orientation and thereby stabilize. Narratives are "intermediators between the individuals' internal structures and the social collective" (Hermwille, 2016, p. 240). The observation of narrative self-reference might give a better or additional understanding of what makes a difference for the system. Thus, it might be useful for mediation and policy and technology assessment.

\subsection{Legitimation as entanglement in a role play}

Technology Assessment analyzes the development and consequences of socio-technical systems, such as automation or renewable energies. The following part focuses on empirical acceptance and thus discusses the role of narratives for empirical legitimation through procedures. Empirical legitimacy is "a generalized willingness to accept undefined decisions within certain limits of tolerance" (Luhmann, 2013, p. 28). Luhmann does not justify the acceptance of undefined 
consequences "as the result of a personal decision" or the rightness of normative arguments, but as based "on a social climate that institutionalizes the recognition of binding decisions as a matter of course" (Luhmann, 2013, p. 34). Thus, institutionalized participatory procedures and legal cases are carried out in order to "build a cooperative audience from case to case" (Luhmann, 2013, p. 209). Such institutionalized "entanglement[s] in a role play" take starters into account that provide context and suspense gradually integrating the interests, references, personality, arguments, and believable sub-histories of those involved in a collectively shared history of interaction (Luhmann, 2013, p. 87):

"As the process evolves, the actors' opportunities for action converge. Everyone has to take account of what he has already said or omitted to say. Amendments bind. Missed opportunities do not return." (Luhmann, 2013, p. 45)

The uncertainty and the prospect of not everything being decided yet motivate for further participation and thus must be "maintained during the procedure with all due care and means of ceremonial." (Luhmann, 2013, p. 116). This uncertainty is suspense by the only certainty that closure will be reached at the end of the procedure in reference to the legal system or previous set public rules. The open opportunity to take on the perspective and to participate is more important than actual participation for preventing mistrust (Luhmann, 2013, p. 123). This opportunity is granted by a followable, and medially spread narrative about the particular case and a culturally shared metanarrative of the generalized case. Legitimation is mainly achieved by the "social behavior" and "symbolically expressive action" (Luhmann, 2013, p. 224). The participants will be given a "new past" in the procedure (Luhmann, 2013, p. 43). A realistic drama is performed whose rules of intelligibility, truthfulness and appropriateness are sought and determined in the process so that a coherent, understandable reception is possible. Consensus on the outcome can only be assumed by the recurring presence combined with the public pressure to find and keep an agreement as a basis of further concerns. In the end the subsequent and shared reception of the proceedings decide over the legitimation:

"The future is the future only as the future of a present-with-past; [...] My consensus is consensus only on your consensus, but my consensus is not your consensus"

(Luhmann, 1987, p. 113)

To sum up, the legitimation through processes are based on institutionally provided role play entanglements following public rules whose spread and shared narratives force the participants to keep on their new given past. In our narrative perspective, empirical legitimation is the result of narrative self-references that positively frame the process of decision making.

\subsection{The internet as technical infrastructure for emerging self-reference}

The same way as by institutional procedures, self-organization can be stimulated by technical infrastructures. Dolata and Schrape (2018) describe new ways of the emergence of collective behavior based on internet infrastructures. According to them, the prerequisite is a technological infrastructure that enables the visibility of one's own action and allows feedback mechanisms - it provides social space of observable interaction. Taken the metaphorical "code is law", code and algorithms are not neutral but technically regulate these conditions for visibility and interaction (2006). Unorganized individuals may behave as an aggregate at comparable orientation and observable patterns emerge. The referring to these emerging patterns of basal self-reference of e.g. swarm consumption, likes or rating-feedback systems leads to a processual self-reference: The recognition of certain previous events becomes of present importance with implication for the future. For example, the mass sharing of a tweet or the establishment of a hashtag gives evidence of 
the possibility of a partial normality to which one can reflexively refer. Further self-reference, such as the established hashtag in new contexts, promotes the reflection and negotiation of shared views, goals, competencies, and principles of communities or publics. In their study, Dolata and Schrape (2018) show that on one hand, the Internet becomes the primary base of communities and social movements; on the other hand, these collectives become dependent, platform owners are gaining power and open code alone does not make an open society. The authors emphasize that technical infrastructures have a major impact on the formation of collective actors, but in addition to digital features, social organization and structuring services are still indispensable.

With means of narrative theory, we attribute the condition of possibility of this processual pattern recognition to cultural meta-narratives and their narrative closure: The social system recognizes this peculiarity in the form of reflection, for example by communicating that "there are still a few missing for the first 1000 likes", "we're going viral" - which frames this observed event in a bigger and meaningful narrative. From now on, explanatory references follow the principle of narrative closure and shape the system boundaries. Appropriate behavior becomes recognizable, criticisable, expectable and plannable. Further communication practice leads to further elaboration, shaping, and distinctive generalizations. What we may perceive on the surface is, from this perspective, not personal opinions of individuals in a filter bubble, but the social self-references that contribute to the common narrative identity. Such an antecedent narrative identity offers viable conditions for the formulation of membership conditions and the establishment of an organizational decision-making structure, in order to further suppress contingencies in favor to the masterplot. In the end, such narratives in function as a founding myth may exceed scientific or historical appropriateness (see part 4).

In both cases, the entanglement in a role-play and the reference to patterning collective behavior, the narratives are formulated by reflection following culturally shared masterplots. Spread and remembered narratives make the merge of plan statements the legitimating basis of infrastructure projects or frame patterns of rejection on Twitter as part of a legitimate protest. Especially in times of continuous certainty of the existence of parallel practices and new formative collectives on the Internet, the perspective of narrative self-references offers a meaningful orientation with regard to personal and organizational accountabilities.

\subsection{Authorized games of make-believe}

In the perspective of pretense theory, many adult activities are best understood as continuations of children's make-believe (Walton, 1990). Following Walton, we can imagine fictional worlds as games to learn from with means of props like novels and literature. The above-mentioned narrative examples of participatory processes or the emergence of protest movements can already serve as an invitation, that is, as the "principle of the generation" of such a game (Walton, 1990, p. 69). For example, prior to a lawsuit, experienced lawyers can play a case according to the legal rules. In imagination, they can estimate whether it makes sense to actually start a lawsuit. Even before protest or terrorist groups occur in the public, patterns of collective behavior on the Internet are observed and evaluated by means of algorithmic pattern recognition. In games of make-believe, these datamodels are "representations" that serve as props for generating "fictional truths by virtue of their features" (Walton, 1990, p. 138). These props distinguish such games from pure day-dreaming - if what is "to be imagined" under these props is authorized by public rules. The fiction view on models assumes that scientific and technical questions can be explored in an imagined context:

"We explore and develop models in the imagination, from an internal or participatory perspective. And we originally compare models and targets from within an extended imagined 
context. In this case, we are fully immersed in the game and we assume an attitude of imagination towards the relevant propositions. However, we can also exit the game and assume an external and descriptive perspective..." (Salis, 2016, p. 256).

In games of make-believe, e.g. engineering students actually imagine to design a machine, reactor or circuit. As an immersed participant, one has the opportunity to imagine what each component does and question intermediate results for plausibility and completeness, such as size, design, and cost of the imaginary machine. Distanced computers do not participate in the game and question their results and intermediate results only on instruction. The users of the model learn about the transferability and plausibility of the results when dealing with the model within a game of makebelieve. On the other hand, one can exit the game and analyze consistency and whether the game is authorized, i.e. is based on public rules:

"Representations are things that possess the social function of serving as props in authorized games of make-believe [...] Games based on public rules are 'authorized'; games involving ad hoc rules are 'unauthorized'. By definition, a prop is a representation if it is a prop in an authorized game." (Frigg 2010, p. 259)

With means of public rules self-referencialy refer to the science system, you can argue for the validity of the representation and modeling results. Outside of a scientific community, model assumptions and rules are neither explicitly known nor considered to be set, but have practical meaning. If there is no insight and no common authorized reference, for example in practical, interdisciplinary and transdisciplinary projects, "narratives can show what experiences one must make in order to keep the use of certain general concepts for the right reaction to the world" (Hampe et al., 2016, p. 21). Such interaction makes sense of its system boundaries on practical constraints and the constraints of the self-referential science system in narrative self-reference. Thus, explicit narratives in sciencebased modeling improve collaboration and reproducibility by establishing, organizing and evolving the shared problem-solving perception with transparent references to established and considered scientific rules. They help to generate and guide through the authorized game of make-believe, highlight what is to experience in every followable step, and how additional assumptions and contingencies about practical concerns have been considered. On one hand, you can immerse, and follow the narrative in a fictional model-world-comparison and reflect affordable plausibility and completeness. On the other hand, you can exit, and analyze the logical consistency of authorization references and interpretation. The latter seems either carried out systematically to a certain depth in peer-review and by the expected perception or when something does not seem plausible. For example, in case of surprise, the better life-cycle assessment of aluminum foil compared to a reusable snack box (see Wellenreuther \& Drescher, 2013) might pose questions that go beyond the application of ISO norms. The need for an authoritative narrative framework for modeling is already reflected and implemented in the concept of the open source project "Jupyter": the narrative form of "computational narratives" is designed to facilitate collaboration, interpretation, and reproducibility through an interplay of models and narratives (Perez \& Granger, 2015). Such narratives can also be understood as hermeneutic chapters that interrupt continuous interrogation and keep a particular section of the world stable for a certain period of time. Although further analytical and empirical evaluation is still pending, this practical achievement seems to address some practical challenges in engineering, consulting, and forecast.

\subsection{Pragmatic constraints on narrative identity}

Narrative self-reference refers to system identity in the distinction of system and environment. In the context of the following theories, narrative self-reference for social systems is referred to as tradition 
(MacIntyre, 2007), cultural community (Bruner, 1990) or "the natural third-person view of her history" (Schechtman, 2015, p. 398) and for persons as their narrative identity (Bruner, 1990; Schechtman, 2015). Narratives constitute the pragmatic "pivot between the realms of the social and the psychological" (Kirmayer, 2007, p. 363):

"In basic outline, then, the "Narrative Self-Constitution View says that we constitute our identities as persons by generating and operating with an autobiographical narrative that meets the articulation and reality constraints." (Schechtman, 2015, p. 398)

This "implicit autobiographical narrative" serves "as the lens" through which persons "experience and act on the world" and cause effects that "constitute personhood" (Schechtman, 2015, p. 396). We neither need nor can assume continuous consciousness of our autobiographical narrative since we only refer to it stepwise. The implicitness of the narrative closure in practice allows inconsistency and gaps in our autobiographical narrative to a certain level since not every aspect is marked in the present narrative self-reference. There is no need for a narrative to tell every detail, as soon as we get an idea of the implicit closure, i.e. keep asking "what comes next?". Thus only gradually, we are forced to extend a story with additional assumptions that make it more coherent or believable in the present context.

In practice, we are only "co-authors" and depend on continuations and constraints of narratives that have already started, "each of us being the main character in his own drama plays subordinate parts in the dramas of others, and each drama constrains the others" (MacIntyre, 2007, p. 213). Bruner and MacIntyre, compare the embeddedness of our life in an ongoing history of traditions metaphorically with a stage, where "others on stage already have a sense of what the play is about, enough of a sense to make negotiation with a newcomer possible" (Bruner 1990, p. 34). Through this cultural embeddedness, we learn about "interpretive procedures for adjudicating the different construals of reality" (Bruner 1990, p. 95), become "the prisoners of the masterplots we grow up with" (Abbott, 2011, p. 189), and we are educated "into the virtues" (MacIntyre, 2007, p. 216). The "fruit of our experience enters into our judgment of narrative fictions" (Abbott, 2011, p. 157) so that our narrative identity is not determined by our social environment, but we can access and emancipate from certain dependencies in reflection. Thus, MacIntyre takes narrative self-reference as a basis for moral reflection:

"I can only answer the question 'What am I to do?' if I can answer the prior question 'Of what story or stories do I find myself a part?'." (MacIntyre, 2007, p. 216)

The implicit reference to our tradition or cultural contexts allows assuming accountable subjects. Being subject of a narrative makes you practically "accountable for the actions and experiences which compose a narratable life", and to "be able to respond to the imputation of strict identity" (MacIntyre, 2007, p. 217). Because the narrative self-reference takes place in society, we can only listen and learn about our constraints and about our perspectives on criticism. Storylistening and storytelling as societal virtues provide the environmental conditions for orientation:

"The ethics of storytelling has its necessary counterpart in the ethics of listening, of witnessing and taking part in the creation of community through compresence." (Kirmayer, 2007, p. 379)

In most cases, we implicitly follow our traditions, normality expectations, and methods, or relate to truth, laws, scarcity of resources, and standards. By story-listening, we get a better idea of how such constraints make a difference for an individual or collective actor and how we can build upon. And by storytelling - in contrast to trials of distant reporting - we set referable system boundaries, shape our identity and become accountable characters in different narratives. 


\section{Narrative self-reference for the assessment of knowledge}

The assessment of knowledge becomes apparent when it has an ambiguous meaning in different structures. Scientific communities formulate observations in systematic self-referential forms of relative context-free condensed expectations and reflect progress only towards their own recent and long-term history (Luhmann, 1992, pp. 136-137). The science meta-narrative is about the anonymous and uninterested experience - what is observed has happened to the observer, so that this knowledge should be accessible to all despite different interests (Luhmann, 1992, p. 143). In references to this meta-narrative, science organizations and interaction actualize their present histories of suspense and surprise in the form of doubts, successes, setbacks, splits and changes in the field of research. These narrative self-references give a convincing, culturally widespread but simplified orientation that does not necessarily have to be shared. All communication is only against the background of functional systems without being able to withdraw to only one functional system. The scientific distinction between truth and untruth emerged historically from the doubt of the sensory perception and, as a second order observation, questions the relation of knowledge to the scientific system (Luhmann, 1992, pp. 167-169). This distinction als serves for authoritarian reasons (Luhmann, 1992, p. 149). It is practically blurred with claims that emphasize honesty and truthfulness to legitimize the quality of an observation that is anyways still to distinquished from an scientific observer (Luhmann, 1992, p. 274). By mentioning relativism, historicism (p. 502), deconstructivism, and the "new literary forms" (p. 93), Luhmann (1992) criticizes that these concepts of self-reference cannot explain the systematic self-references of a unique science system:

"For if one observer can observe what another person cannot observe, a communication barrier has been established which cannot be broken without destroying the observation of one or the other, the primary or the secondary observer." (Luhmann, 1992, p. 503)

The concept of narrative self-reference doesn't aim to explain the unity of a science system but to explain, address and find ways to deal with the phenomenon of such established barriers of selfreferentiality. The self-entanglement in a role play explains the self-referencial establishment of exactly such barriers on side of institutions that hold and focalize the said (see part 3.1). New infrastructures enhance and control the development and stabilization of publics and movements, which nevertheless continue to depend on social structuring through, for example, narrative interpretation (see part 3.2). Application oriented research must take values, norms and interests of the field of application into account, otherwise one misses the sector of application-oriented research and does not meet market requirements (Luhmann, 1992, p. 640). The narrative view situates these aspects in public key-narratives, such as stakeholders' self-descriptions, visions, opinion articles, participation process reports and narrative expectations - here, empirical links must be sought (see part 3.4 and part 2): As we can immerse or methodically analyze meaning inside the sequentiality of a narrative, we can overcome the formal "incommensurabilities" and further barriers of formal structures. Especially in case of models as mediators and because the scientific achievements must later be translated back, the narrative form is seen as an accompanying framework of practice-oriented and interdisciplinary research that determines which aspects are in a certain case taken into account (see part 3.3). On the social dimension, stakeholders emerge when the narrative self-reference meets subjects of the model - this is also the case for public narrators on side of the science. On the factual dimension, the narrative serves as a negotiation about model references and decisions. 


\subsection{The rigor of power and the rigor of truth}

The factual dimension of a narrative can be in conflict with the socio-political dimension.

Semantically such a conflict is the normal political struggle about the contingent self-reference of a social system on the horizon of present concerns. In juxtaposition to the expected narrative closure, the narrative may lack continuity or, when the conflict is about adequateness of system boundaries, lack coherence. The implied normality expectations of the narrative give a scope of what and how aspects are taken into account. For example, in a technical project, the stakeholders decide whether to respect, weighting and focalize certain ecological and economic impacts or to neglect and actively prevent them in favor of a preferred storyline. Knowledge could cause unpleasant surprises in ideological storylines, i.e. storylines that rely on the ignorance of contingency (Bruner, 1990, p. 96; Luhmann, 1987, p. 281). Thus, there is a risk and possible interest of ideologists and organizations to hold on to given system boundaries and ignore the knowledge about e.g. human toxicology of agrochemicals within their given possibilities - at least for a certain phase.

To give a historical example, in "Rigorismus der Wahrheit", Blumenberg criticizes Hannah Arendt's report on the Eichmann process not in terms of her scientificity, but in her neglect of its function as a founding myth of Israel state (Blumenberg, 2015, pp. 77-78). Even when Arendt's scientific work was factually right, her report competed with existing narratives and masterplots. The trial and execution of Eichmann already had a meaning following the masterplots of symbolic vengeance and compensation and providing narrative closure to the Jewish persecution history in Israel state. As a result, Arendt experienced a harsh criticism that was untypical of a scientific work. Even Blumenberg discredits Arendt's intended honesty of truth with gross artistic extravagance (2015, p. 98). Taking the exaggerations of Blumenberg, some rigor of power would maybe insist on a populist narrative providing only the most relevant consent, and some rigor of truth on a narrative providing only the most evidence. The rigor of power sets boundaries on the factual perspective by insisting on the normality expectations. The rigor of truth denies boundaries on the factual perspective but ignores the social meaning of its provided narrations. From a system-theoretical perspective, interaction systems and organizations communicate against the background of the functional systems and must deal with these respective restrictions without being able to withdraw to a system: "knowledge function and political function cannot be separated" (Luhmann, 1992, p. 149). Blumenberg concludes that "it seems indispensable that alliances between history and truth are standard to our assessment of both" (2015, p. 93). Such alliances are not just resulted in compromises or contradictive models, but the practical effort to find a viable and adequate negotiation.

The reflection on the narrative self-reference offers different options to adapt and focalize political and scientific feedback as a framework for "peacekeeping" or ongoing critique (Bruner, 1990, p. 95). When expectations are seriously disappointed, for example, in cases of serious diseases, political changes, disappointing modeling results or personal blow, a shift of narratives can reframe perspectives of social systems, individuals or technology, and focalize properties differently. MacIntyre elucidates an identity crisis as the unintelligibility of the narrative that "lacks any point, any movement towards a climax or a telos." (MacIntyre, 2007, p. 217). The virtue and recognition of listening and narration help to stepwise explore new narrative closure through the stability of ongoing practices. Therefore narratives must be recognized in their power to make "all suffering bearable", "do that reconciliation with reality" (Arendt, 1969, p. 367), and even provide viable perspectives with irreconcilable conflicts, such as fulfilling life and inevitable death (Abbott, 2011, p. 55). The practical challenge is to find a viable way between the constant flexibility of the narrative self-reference in parallel practices and systems' constraints and a continuity that allows orientation and the choice of our direction. The key story could be that, despite implicit ignorance, science provides in the long run decontextualized compatible and useful knowledge structures and public 
rules that serve as second-order observers for the contextualized interplay of models and narratives. But the long-term view is no guarantee that scientifically meaningful measures will be implemented in good time. Nevertheless, the richness, possibilities, and function of the narrative seem promising for the negotiation of power and truth:

"I sometimes think that we are not lacking in learned prose but in learned poetry. Scientific theories have a peculiar content of the world, which they themselves cannot even formulate (with all incorporation of self-referentiality). The so inadequate attempts at a political interpretation of the "actual" proposition of theories point to this need for a second version, without being able to adequately satisfy it. Perhaps it should instead give a kind of parallel poetry for demanding theoretical work, which says everything differently again and thus rejects scientific language into the limits of its functional system." (Luhmann, 1993, pp. 176-177)

\section{Conclusion and outlook}

The abstractness of social systems' theory makes it capable to reflect its conditions of observation in the juxtaposition of other observers. The aim of this article was to show how a perspective of literary theory can be adapted in social systems theory as a concept of a narrative self-reference. As more and more texts about the corporate identities, visions and concerns become public or online available as a data source, the methods of literary theory seem quite promising for the analysis of social systems - or as a supplement of surveys, network analysis, modeling and other forms of policy and technology assessment. In order to provide further insights towards the knowledge assessment against the only contingent background of the science system, narratives are observed in forms of whole lingual structures that serve as self-reference for social and psychic systems and thus become essential and powerful. Narratives give insight of "what matters how to the system in view of the system": Processual self-reference refers to the sequentiality of events. Reflection refers to the implied system boundaries of this sequentiality to present distinctions. The narrative selfconstitution view explains the cognitive meaning of narratives and reality constraints of societal embeddedness. The extended view on narrative self-reference merges this tradition with ongoing research on systems, legitimation and philosophical pretense theory. Narratives are thus taken as the meaningful guidance and boundary of individual and collective action and collaboration - as already applied in psychotherapy, environmental psychology, political science, data science and foresight (Brown, 2017; Jones \& McBeth, 2010; Kirmayer, 2007; Perez \& Granger, 2015; Schwarz, 2015). For model-based practices, narratives support reproducibility by establishing, organizing and evolving a shared problem-solving perception with transparent and selective references to prevailing public rules. As an outlook, further analytical distinctions must be made to define and reason about the distinct empirical properties of a narrative that provide distinct functions in scientific modeling practice of socio-technical concerns. However, the benefit of this theoretical concept has to prove itself practically. Our further studies aim to empirically elaborate the perspective of the modelsnarrative-interplay on cases of bioeconomy for real-time policy and technology assessment: Can this reflection on narrative self-reference in practice support the appropriate use of narratives as a viable, dynamically stable common ground for knowledge-based policies and modeling practice?

\section{References}

Abbott, H. P. (2011). The Cambridge introduction to narrative (2. ed., 7. print). Cambridge introductions to literature. Cambridge u.a: Cambridge Univ. Press.

Arendt, H. (1969). Wahrheit und Politik. Philosophische Perspektiven : Ein Jahrbuch. 
Aristoteles. (2006). Poetics. Sachs, Joe (trans.). Focus philosophical library. Newburyport, Ma: Focus Publ.

Meyer, A. (Ed.). (2015). Rigorismus der Wahrheit: "Moses der Ägypter" und weitere Texte zu Freud und Arendt (1. Auflage). Berlin: Suhrkamp.

Brown, P. (2017). Narrative: An ontology, epistemology and methodology for proenvironmental psychology research. Energy Research \& Social Science, 31, 215-222. https://doi.org/10.1016/j.erss.2017.06.0o6

Bruner, J. (1990). Acts of meaning. Cambridge, Mass.: Harvard Univ. Press.

Crasnow, S. (2017). Process tracing in political science: What's the story? Studies in History and Philosophy of Science, 62, 6-13. https://doi.org/10.1016/j.shpsa.2017.03.002

Culler, J. (2011). Literary Theory: A Very Short Introduction (2nd ed.). Very Short Introductions. Oxford: OUP Oxford.

Dolata, U., \& Schrape, J.-F. (2018). Collectivity and power on the internet: A sociological perspective. Springer Briefs in Sociology. Wiesbaden.

Frigg, R. (2010). Models and fiction. Synthese, 172(2), 251-268. https://doi.org/10.1007/s11229009-9505-0

Hampe, M., Gabriel, G., Gehring, P., Ernst, G., Jaeggi, R., Tetens, H.,. . Reuter, G. (2016). Die Lehren der Philosophie: Eine Kritik (Erweiterte Ausgabe, erste Auflage). Suhrkamp Taschenbuch Wissenschaft: Vol. 2187. Berlin: Suhrkamp.

Hermwille, L. (2016). The role of narratives in socio-technical transitions-Fukushima and the energy regimes of Japan, Germany, and the United Kingdom. Energy Research \& Social Science, 11, 237-246. https://doi.org/10.1016/j.erss.2015.11.001

Jasanoff, S., \& Simmet, H. R. (2017). No funeral bells: Public reason in a 'post-truth' age. Social Studies of Science, 47(5), 751-770. https://doi.org/10.1177/0306312717731936

Jones, M. D., \& McBeth, M. K. (2010). Narrative Policy Framework: Clear Enough to be Wrong? Policy Studies Journal, 2(38), 329-353. Retrieved from http://works.bepress.com/mjones/3/

Kirmayer, L. J. (2007). Failures of imagination: The refugee's predicament. In Understanding trauma : integrating biological, clinical, and cultural perspectives (pp. 363-381). New York [u.a.]: Cambridge University Press.

Lessig, L. (2006). Code: Version 2.o ([2. ed.]). New York, NY: Basic Books. Retrieved from http://codev2.cc/download+remix/Lessig-Codev2.pdf

Luhmann, N. (1971). Sinn als Grundbegriff der Soziologie. In J. Habermas \& N. Luhmann (Eds.), Theorie Theorie-Diskussion. Theorie der Gesellschaft oder Sozialtechnologie: Was leistet die Systemforschung? (1st ed.). Frankfurt am Main: Suhrkamp.

Luhmann, N. (1987). Soziale Systeme (15th ed.). Frankfurt am Main: Suhrkamp. 
Luhmann, N. (1992). Die Wissenschaft der Gesellschaft (1st ed.). Frankfurt am Main: Suhrkamp.

Luhmann, N. (1993). Soziologische Aufklärung 3: Soziales System, Gesellschaft, Organisation (3. Aufl.). Soziologische Aufklärung: / Niklas Luhmann ; 3. Opladen: VS Verl. für Sozialwiss.

Luhmann, N. (2013). Legitimation durch Verfahren (9th ed.). Frankfurt am Main: Suhrkamp.

MacIntyre, A. (2007). After Virtue: A Study in Moral Theory, Third Edition. Notre Dame IN: University of Notre Dame Press.

Morgan, M. S. (2017). Narrative ordering and explanation. Studies in History and Philosophy of Science, 62, 86-97. https://doi.org/10.1016/j.shpsa.2017.03.006

Perez, F., \& Granger, B. E. (2015). Project Jupyter: Computational Narratives as the Engine of Collaborative Data Science. Retrieved from Helmsley Trust; Gordon and Betty Moore Foundation; Alfred P. Sloan Foundation website: http://archive.ipython.org/JupyterGrantNarrative-2015.pdf

Salis, F. (2016). The Nature of Model-World Comparisons. The Monist, 99(3), 243-259. https://doi.org/10.1093/monist/onwoo3

Schechtman, M. (2015). Dissociative Identity Disorder and Narrative. In J. Clausen \& N. Levy (Eds.), Handbook of Neuroethics (pp. 393-405). Dordrecht: Springer Netherlands. https://doi.org/10.1007/978-94-007-4707-4_113

Schwarz, J. O. (2015). The "Narrative Turn" in developing foresight: Assessing how cultural products can assist organisations in detecting trends. Technological Forecasting \& Social Change : an International Journal, 90(2), 510-513.

Von Förster, H. (1972). Perception of the Future and the Future of Perception. Instructional Science, 31-46.

Walton, K. L. (1990). Mimesis as make-believe: On the foundations of the representational arts. Cambridge, Mass.: Harvard Univ. Press.

Wellenreuther, F., \& Drescher, A. (2013). LCA study of two different sandwich packs: A rigid plastic lunchbox and household aluminium foil: Prepared for the European Aluminium Foil Association e.V. critically reviewed according to ISO 14040, 14044. Heidelberg. Retrieved from ifeu website: www.alufoil.org/files/alufoil/sustainability/lcastudy/EAFA_Sandwich_Executive_Sum mary_EN.pdf

Wittgenstein, L. (1984). Werkausgabe. Frankfurt a.M: Suhrkamp. Retrieved from http://www.geocities.jp/mickindex/wittgenstein/witt_pu_gm.html 